\title{
CIRURGIA SEGURA: ELABORAÇÃO E VALIDAÇÃO DE UM CHECKLIST PARA PROCEDIMENTO CIRÚRGICO AMBULATORIAL
}

\author{
Paula Cristine Figueiredo Cavalari \\ Enfermeira. Supervisora do Centro Cirúrgico do Hospital de Clínicas da Unicamp \\ cavalari@hc.unicamp.br
}

INTRODUÇÃO: As listas de verificação são instrumentos que auxiliam os profissionais a prevenirem a ocorrência de eventos adversos e para isso, a Organização Mundial da Saúde (OMS) desenvolveu um checklist com o intuito de garantir a realização de cirurgias seguras. Entretanto, verificamos que esta lista não está totalmente adequada à realidade dos centros cirúrgicos ambulatoriais. OBJETIVOS: Desenvolver e validar um checklist de verificação de cirurgia segura específico para procedimentos cirúrgicos ambulatoriais. MÉTODO: Estudo metodológico, constituído por três etapas: na primeira, o checklist foi construído tendo como base o instrumento da OMS e a literatura científica sobre centro cirúrgico ambulatorial. Na segunda etapa, o instrumento foi submetido à avaliação de um grupo de cinco juízes com reconhecido saber na área do estudo'com o intuito de validar o conteúdo do instrumento. Para essa validação, a análise da relevância/representatividade de cada um dos itens que compuseram o instrumento foi avaliada por meio de uma escala tipo Likert com quatro pontos. Após a avaliação dos juízes, em cada uma das rodadas, as respostas foram tabuladas e foi calculado o Índice de Validade de Conteúdo (IVC) e valores superiores a 0,8 são considerados satisfatórios. RESULTADOS: Foram necessárias três rodadas para que todos os itens/momentos atingissem IVC superior a 0,8. Foram realizadas modificações em 30 itens e em dois momentos, pois não alcançaram a concordância mínima estabelecida nas primeira e segunda rodadas. $\mathrm{Na}$ terceira rodada, o consenso entre os juízes foi alcançado. Dessa forma, a versão final do instrumento ficou composta por 64 itens distribuídos em cinco momentos: Cabeçalho (11 itens); Admissão do paciente (oito itens); Sala de preparo (10 itens); Antes do início da cirurgia/procedimento (15 itens); Antes da saída da sala operatória (11 itens) e Antes da saída do centro cirúrgico (nove itens). CONCLUSÃO: O instrumento denominado "Checklist de Cirurgia Segura para Procedimento Ambulatorial" foi construído e validado com sucesso 
e sua implementação nos serviços de saúde pode contribuir sobremaneira para a segurança do paciente submetido à procedimentos cirúrgicos ambulatoriais.

Palavras-chave: Estudos de validação. Lista de checagem. Procedimentos cirúrgicos ambulatórios. 